\title{
Pediatric Prevalence of Clostridium difficile Infection in a Tertiary Care Hospital
}

${ }^{1}$ Chetana Vaishnavi, ${ }^{2}$ Megha Sharma, ${ }^{3}$ Babu R Thapa

\begin{abstract}
Background and objectives: Clostridium difficile is the etiological agent of healthcare-associated infections in adults. Recently, C. difficile is being considered as a gastrointestinal pathogen in pediatric patients. A retrospective investigation was carried out in a tertiary care hospital to look for the pediatric prevalence of $C$. difficile infection (CDI) in different age groups.
\end{abstract}

Materials and methods: The patient population investigated for CDI was categorized into infant group (0-2 years), early childhood group $(<2-12$ years) and teenage group $(<12-19$ years). Clinical and demographic information were retrieved from laboratory records.

Results: A data of 1033 patients $(0-19$ years; $M: F=667: 366)$ the male gender was significant $(p<0.0001)$. Statistical significance $(p<0.0001)$ was observed between the three age groups (infant group, $n=241$; early childhood group, $n=424$; teenage group, $n=368$ ). The major underlying ailments were gastrointestinal symptoms (31.9\%) and malignancies (24.2\%). C. difficile toxin (CDT) was positive in $22.07 \%$, and significant $(p=0.000)$ in all the groups. Clinical symptoms were bloody diarrhea $(9.87 \%)$, watery diarrhea $(57.31 \%)$, fever $(53.05 \%)$ and abdominal pain (34.56\%). The frequency of diarrhea was significant $(p>0.0001)$. Antibiotic use with clinical symptoms showed significance with watery diarrhea $(p=0.000)$ and fever $(p=0.000)$. Abdominal pain was found to be significant $(p=0.007)$ when correlated with CDT positivity. The CDI was positive in a total of $46(27 \%)$ patients on first follow-up $(n=170)$. When variables of patients in the repeat follow-up $(n=47)$ were compared with their primary admission data and that of first follow-up, significant difference was seen.

Conclusion: The CDI is commonly present in hospitalized pediatric patients, but clinical symptoms and suspicion can aid the final diagnosis.

Keywords: Antibiotics, C. difficile infection, Clinical symptoms, Follow-up, Pediatric patients.

How to cite this article: Vaishnavi C, Sharma M, Thapa BR. Pediatric Prevalence of Clostridium difficile Infection in a Tertiary Care Hospital. J Gastrointest Infect 2018;8(1):5-11.

Source of support: Nil

Conflict of interest: None

\footnotetext{
${ }^{1,3}$ Professor, ${ }^{2}$ Senior Research Fellow

${ }^{1-3}$ Department of Gastroenterology, Postgraduate Institute of Medical Education and Research, Chandigarh, India

Corresponding Author: Chetana Vaishnavi, Professor, Department of Gastroenterology, Postgraduate Institute of Medical Education and Research, Chandigarh, India, Phone: 911722756609, e-mail: cvaishnavi@rediffmail.com
}

\section{INTRODUCTION}

Clostridium difficile is a Gram-positive spore (GPS) forming bacillus, producing two potent toxins known as toxin A and toxin B with enterotoxin and cytotoxic properties. This microorganism is generally transmitted to humans through the fecal-oral route. Spores from toxigenic isolates easily survive the acidic milieu of the stomach and colonize the lower part of the intestine. ${ }^{1}$ C. difficile is the etiological agent of healthcare-associated infections and is responsible for essentially all cases of pseudomembranous colitis (PMC) and approximately $20 \%$ of cases of less severe intestinal disease including nonspecific colitis or diarrhea due to antibiotic usage. ${ }^{2}$ In a few cases, CDI can lead to life-threatening toxic megacolon, septic shock and/or death. ${ }^{3}$

Under two years of age, children, in general, are carriers and do not exhibit clinical disease. ${ }^{4}$ Colonization in infants reduces to less than $5 \%$ by 2 years of age, akin to the adults. ${ }^{5}$ It is unclear if it corresponds to temporary colonization or is a constituent of stable flora. The precise means of protection of the infants against CDT is unclear because the titers of CDT in fecal samples of healthy infants are comparable to those found in adults with CDI. ${ }^{6}$ It has been suggested that infants may not possess the cellular mechanism to bind the toxin for processing ${ }^{7}$ or that infants are protected by antibodies in breast milk and protective commensal gut flora. ${ }^{8}$

Inconsistent reports exist in the literature concerning the in vivo production of CDT in infants. Cytotoxin was demonstrated by Larson et al. ${ }^{9}$ in the stool of two healthy infants colonized by C. difficile, whereas Cashore et al. ${ }^{10}$ reported specific cytotoxicity in the stool of five infants with necrotizing enterocolitis. Stark et al..$^{5}$ by expressing the in vitro cytotoxigenicity of infant $C$. difficile strains, refuted the notion that infants have only non-toxigenic strains and do not develop PMC. Adler et al. ${ }^{11}$ and Donta et al. ${ }^{12}$ have also reported PMC in some infants.

The prevalence of $\mathrm{CDI}$ in adult population along with the risk factors involved ${ }^{13}$ in its precipitation has been well investigated, but in case of pediatric population the literature is scanty. ${ }^{14} \mathrm{As} \mathrm{CDI}$ in adults is increasing , simultaneously the rates of hospitalized children with CDI are also increasing, probably due to improved reporting and attention paid to CDI in children. Consequently, there has 
been a recent increase in interest regarding the role of $C$. difficile as a pathogen in pediatric gastrointestinal disease.

Because of the contrary reports, the surveillance of the prevalence of CDI in pediatric patients becomes very important. In the present observational study, retrospective data of pediatric patients from a tertiary care hospital were analyzed with the following objectives: (i) To evaluate the prevalence of CDI, confirmed with stool toxin analysis, in pediatric patients of different age groups (ii) To look for the association of CDI with antibiotic use and with clinical symptoms and (iii) to correlate the available follow-up data with the initial admission data. Pertinent clinical aspects and demographic information, diagnosis, therapy, antibiotic exposure, and hospitalizations were reviewed. ${ }^{15}$

\section{MATERIALS AND METHODS}

This study was approved ethically by the Institute Ethical Committee, and the investigation was carried out during a period ranging from October 2009 to April 2017.

\section{Patient Population}

Fecal samples from consecutive pediatric patients received in the Microbiology Division, Department of Superspecialty of Gastroenterology, formed the basis of the investigation. These samples were sent with the specific request by the clinicians for CDT assay, based on clinical suspicion. These patients belonged to the medical and surgical wards of the hospital and were undergoing treatment for various ailments related to gastrointestinal disorders, malignancies, and other conditions.

During analysis the patient population was categorized by age into three groups as follows:

- Group 1 (infant group): This group involved infant patients below 2 years of age.

- Group 2 (early childhood group): This group comprised of patients $<2$ years and up to 12 years of age.

- Group 3 (teenage group): In this group, patients $<12$ years and up to 19 years were included.

\section{C. difficile Toxin Assay}

C. difficile toxins A and B were detected in the fecal samples of these patients using enzyme-linked immunosorbent assay (ELISA) kits (DRG-International Inc, USA) as per the manufacturer's instructions. The results were read in an ELISA reader (Tecan Infinite F50, Austria) at $450 \mathrm{~nm}$.

\section{Clinical and Demographic Analysis}

Meticulously noted laboratory records of all the included patients were reviewed for patient demographics, clinical symptoms, medical history, therapy, etc. Similar records for all first and second follow-up were also retrieved.

\section{Statistical Analysis}

The data were entered into an excel master sheet and analyzed by using non-parametric Binomial test. Descriptive statistics was used to compare the range of frequency and duration of diarrhea. The data on CDT positive and clinical symptoms are presented as a percentage of total outcome. Pearson correlation (2 tailed test) was used to find the correlation among the various clinical symptoms and between CDT and antibiotic receiving status. Comparison of CDT status with antibiotic use was done using non-parametric 2 independent sample t-test. Variables in follow-up patients were compared with primary admission data using chi-square and $p<0.05$ was considered as significant level.

\section{RESULTS}

\section{Demographic Profile of the Patients}

Of the 1033 patients analyzed, 667 (64.6\%) were males and $366(35.4 \%)$ females showing a significant difference $(p<0.0001)$ in gender. The age of the patients, across the total study population, ranged from a few days to 19 years with $8.83 \pm 6.25$ as mean \pm SD. The highest number of enrolled patients was 424 in the early childhood group (group 2) followed by 368 in the teenage group (group 3) and 241 in the infant group (group 1). There was a statistically significant difference $(p<0.0001)$ between the three age groups. The patients had underlying conditions such as gastrointestinal ailments in 329 (31.9\%), followed by malignancy in 251 (24.2\%), renal disorders in 40 (3.9\%) and respiratory problems in $29(2.8 \%)$ of them. Another $316(30.6 \%)$ had a variety of ailments inclusive of neurological and hepatic disorders. In 68 (6.6\%) patients the underlying conditions were not known.

\section{Antibiotic Receiving Pattern}

When the pattern of antibiotic usage was investigated, 156 patients received no antibiotic, 314 received single antibiotic and 563 received multiple antibiotics. When the antibiotic usage between different age groups was checked (Graph 1) it was found to be non-significant in all the three categories (no antibiotic, $p=0.4096$; single antibiotic, $p=0.4096$; multiple antibiotics, $p=0.4362$ ). The major antibiotic groups in use in decreasing order were beta-lactam antibiotics $(58.9 \%)$, glycopeptides $(12.93 \%)$, nitroimidazoles $(11.8 \%)$, fluoroquinolones $(3.96 \%)$, cyclic lipopeptides $(1.55 \%)$, lincosamides $(1.44 \%)$, macrolides $(1.23 \%)$, sulfonamides $(0.80 \%)$, tetracyclines $(0.53 \%)$, antimycobac- 


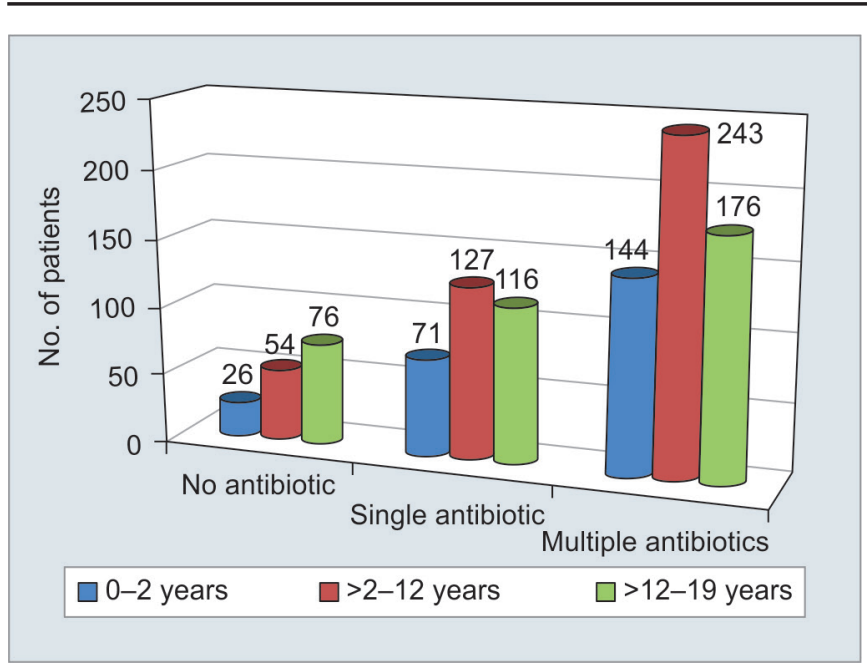

Graph 1: Pattern of antibiotics received by the patients

terial $(0.48 \%)$, aminoglycosides $(0.37 \%)$ and oxazolidinones $(0.37 \%)$. Other therapeutics in use were antifungals $(1.65 \%)$, antiviral drugs $(0.80 \%)$, antiprotozoal agents $(0.35 \%)$, proton pump inhibitors $(1.02 \%)$, corticosteroids $(0.70 \%)$ and immunosup pressants $(0.26 \%)$.

\section{CDT Status and Clinical Profile}

C. difficile toxin was positive in $22.07 \%(n=228)$ of the total patients investigated. In males, CDT positivity was lower (21.6\%) than that in females (23\%), but the difference was not significant $(p=0.7442)$. Among the 228 patients with positive CDT, 47 (20.62\%) belonged to the infant group (group 1), 104 (45.61\%) belonged to the early childhood group (group 2) and $77(33.77 \%)$ to the teenage group (group 3).

Predominant clinical symptoms present in patients were bloody diarrhea in $102(9.87 \%)$, watery diarrhea in $592(57.31 \%)$, the presence of mucus in stool in 378 (36.59\%), fever in 548 (53.05\%) and abdominal pain in $357(34.56 \%)$. When symptoms were statistically checked, abdominal pain was found to be significant $(p=0.006)$ in the early childhood group (group 2) as well as in the teenage group (group 3). Table 1 compares the CDT status and clinical symptoms in different groups of patients.

The data for frequency and duration of diarrhea was available for 144 patients in the infant group, 243 patients in the early childhood group and 176 patients in the teenage group (Table 2). The frequency of diarrhea was 2-50 times (8.40 \pm 5.49 ) in the infant group (group 1), 0-30 times $(6.94 \pm 19.96)$ in the early childhood group (group 2) and 0-31 times (5.75 \pm 47.71$)$ in the teenage group (group 3) and was found to be significant $(p>0.0001)$ with each other. The duration of diarrhea was different in the three groups of study i.e., $52.09 \pm 467.31$ days in the Infant Group, $4.07 \pm 96.37$ days in the Early Childhood Group and $3.68 \pm 324.46$ days in the Teenage Group and they were not significant $(p=0.2927)$.

\section{Association/Correlation of Diverse Factors}

\section{Association of CDT positivity with age group}

The CDT positivity according to age groups was $19.5 \%$ in the infant group (Group 1), $24.5 \%$ in the early childhood group (group 2) and $20.9 \%$ in the teenage group (group 3). The CDT positivity status in the different age groups was found to be significant $(p=0.000)$ in all the groups (Table 1$)$.

However, there was no significant association $(p>0.05)$ with age group for CDT positivity when compared to the sample size of each group.

\section{Correlation of Antibiotic Usage with Clinical Symptoms and CDT Status}

When compared through Pearson correlation test, the correlation of antibiotic usage with clinical symptoms showed significant difference with watery diarrhea $(p=0.000)$ and fever $(p=0.000)$, but the comparison of CDT posi-

Table 1: CDT status and clinical symptoms in different groups

\begin{tabular}{|c|c|c|c|c|c|c|c|}
\hline Parameters & & $\begin{array}{l}\text { Infant group } \\
n(\%)\end{array}$ & $p$ value & $\begin{array}{l}\text { Early childhood } \\
\text { group } n(\%)\end{array}$ & $p$ value & $\begin{array}{l}\text { Teenage } \\
\text { group } n(\%)\end{array}$ & $p$ value \\
\hline \multirow[t]{2}{*}{ CDT status } & Pos & $47(19.5 \%)$ & $0.000^{*}$ & $104(24.5 \%)$ & $0.000^{*}$ & $77(20.9 \%)$ & $0.000^{*}$ \\
\hline & Neg & $194(80.5 \%)$ & & $320(75.5 \%)$ & & $291(79.1 \%)$ & \\
\hline \multicolumn{8}{|l|}{ Clinical symptoms } \\
\hline \multirow[t]{2}{*}{ Bloody diarrhea } & Pos & $16(6.6 \%)$ & 0.061 & $28(6.60 \%)$ & 0.061 & $58(15.8 \%)$ & 0.314 \\
\hline & Neg & 225 (93.4\%) & & $396(93.4 \%)$ & & $310(84.2 \%)$ & \\
\hline \multirow[t]{2}{*}{ Watery diarrhea } & Pos & $151(62.7 \%)$ & 0.392 & $254(59.9 \%)$ & 0.280 & $187(50.8 \%)$ & 0.632 \\
\hline & $\mathrm{Neg}$ & $90(37.3 \%)$ & & $170(40.1 \%)$ & & $181(49.2 \%)$ & \\
\hline \multirow[t]{2}{*}{ Presence of mucus } & Pos & $90(37.3 \%$ & 0.853 & $158(37.3 \%)$ & 0.381 & $130(35.3 \%)$ & 0.164 \\
\hline & $\mathrm{Neg}$ & $151(62.7 \%)$ & & $266(62.7 \%)$ & & $238(64.7 \%)$ & \\
\hline \multirow[t]{2}{*}{ Fever } & Pos & $134(55.6 \%)$ & 0.055 & $241(56.8 \%)$ & 0.800 & $173(47.0 \%)$ & 0.573 \\
\hline & $\mathrm{Neg}$ & $107(44.4 \%)$ & & $183(43.2 \%)$ & & $195(53.0 \%)$ & \\
\hline \multirow[t]{2}{*}{ Abdominal pain } & Pos & $49(20.3 \%)$ & 0.165 & $141(33.3 \%)$ & $0.006^{*}$ & $167(45.4 \%)$ & $0.006^{*}$ \\
\hline & $\mathrm{Neg}$ & $192(79.7 \%)$ & & $283(66.7 \%)$ & & $201(54.6 \%)$ & \\
\hline
\end{tabular}

Pos = positive; Neg = negative; ${ }^{*}=$ significant value 


\begin{tabular}{lllll}
\hline \multicolumn{5}{c}{ Table 2: The frequency and duration of diarrhea in different age groups } \\
\hline Variables & No. of patients & Age groups & Range & $p$ value \\
\hline Frequency (number of & 144 & $0-2$ years & $2-50$ & $<0.0001^{*}$ \\
times per day) & 243 & $<2-12$ years & $0-30$ & $0-2927$ \\
& 176 & $<12-19$ years & $0-31$ & $0-5110$ \\
Duration (in days) & 144 & $0-2$ years & $0-1095$ & $0-5492$ \\
& 243 & $<2-12$ years & $<12-19$ years & \\
\hline
\end{tabular}

tivity was not found to be significant $(p=0.149)$ with antibiotic usage.

\section{Correlation of CDT with Clinical Symptoms}

When clinical symptoms were correlated with CDT positivity, abdominal pain was found to be the most significant $(p=0.007)$.

\section{Follow-up Data}

\section{First follow-up}

Of 1033 patients included during the primary admission, $170(\mathrm{M}: \mathrm{F}=114: 56)$ with age ranging from 7 months to 19 years came for the first follow-up. The patients had underlying ailments such as gastrointestinal symptoms in $62(36.5 \%)$, followed by malignancy in $55(32.4 \%)$, and respiratory problems in $7(4.1 \%)$ of them. Another 39 $(22.9 \%)$ had a variety of other ailments and in $7(4.1 \%)$ patients, the underlying conditions were not known.

There were 39 patients in the infant group, 74 patients in the early childhood group and 57 in the teenage group. Antibiotic usage status was as follows: Infant group (nil $=3$, single $=8$, multiple $=28$ ); in the early childhood group (nil $=7$, single $=21$, multiple $=46$ ) and in the teenage group $($ nil $=19$, single $=14$, multiple $=24)$.
CDI was positive in a total of $46(27 \%)$ patients on first follow-up, with $9 / 39$ (23.1\%) in the infant group, 23/74 $(31.1 \%)$ in the early childhood group and $14 / 57(24.6 \%)$ in the teenage group. When variables of patients in the first follow-up were compared with their primary admission data, highly significant difference was seen in the antibiotic usage, CDT status and clinical symptoms during both the primary admission and follow-up (Table 3).

\section{Repeat follow-up}

There were $47(\mathrm{M}: \mathrm{F}=35: 12)$ patients (1-19 years) among the first follow-up of 170 patients who came for a repeat follow-up during the study period. The underlying ailments in the repeat follow-up patients were gastrointestinal symptoms in 22 (46.8\%), malignancy in 15 (31.9\%), and respiratory problems in $4(8.5 \%)$ of them. Another 6 $(12.8 \%)$ had a variety of other ailments.

There were 7 patients in the infant group, 25 patients in the early childhood group and 15 in the teenage group. Antibiotics received by patients were: Infant group - nil $=2$; single $=2$, multiple $=3$; early childhood group-nil $=4$; single $=5$, multiple $=16$; Teenage Group - nil $=7$; single $=7$, multiple $=1$. CDI was positive in a total of $15 / 47(31.9 \%)$ patients on repeat follow-up (infant group-1/7; early childhood group-11/25; teenage group-3/15). When

Table 3: Comparison of variables between 1st follow-up patients and their primary admission data

\begin{tabular}{|c|c|c|c|c|c|}
\hline \multicolumn{3}{|l|}{$\begin{array}{l}\text { 1st Follow up patients } \\
(n=170)\end{array}$} & \multicolumn{3}{|c|}{$\begin{array}{l}\text { FU patients' primary admission data } \\
(n=170)\end{array}$} \\
\hline Clinical symptoms & & $\begin{array}{l}p \text { values } \\
\text { (Chi-square) }\end{array}$ & Clinical symptoms & & $\begin{array}{l}p \text { values } \\
\text { (Chi-square) }\end{array}$ \\
\hline Bloody diarrhea & $\begin{array}{l}\text { Pos }=96 \\
\text { Neg }=74\end{array}$ & 0.092 & Bloody diarrhea & $\begin{array}{l}\text { Pos }=101 \\
\text { Neg }=69\end{array}$ & $0.014^{*}$ \\
\hline Watery diarrhea & $\begin{array}{l}\text { Pos }=70 \\
\text { Neg }=100\end{array}$ & $0.021^{*}$ & Watery diarrhea & $\begin{array}{l}\text { Pos }=66 \\
\text { Neg }=104\end{array}$ & $0.004^{*}$ \\
\hline Presence of mucus & $\begin{array}{l}\text { Pos }=21 \\
\text { Neg }=149\end{array}$ & $0.000^{*}$ & Presence of mucus & $\begin{array}{l}\text { Pos }=19 \\
\text { Neg }=151\end{array}$ & $0.000^{*}$ \\
\hline Fever & $\begin{array}{l}\text { Pos }=88 \\
\text { Neg }=82\end{array}$ & 0.645 & Fever & $\begin{array}{l}\text { Pos }=100 \\
\text { Neg }=70\end{array}$ & $0.021^{*}$ \\
\hline Abdominal pain & $\begin{array}{l}\text { Pos }=70 \\
\text { Neg }=100\end{array}$ & $0.021^{*}$ & Abd. pain & $\begin{array}{l}\text { Pos }=55 \\
\text { Neg }=115\end{array}$ & $0.000^{*}$ \\
\hline CDT status & $\begin{array}{l}\text { Pos }=46 \\
\text { Neg }=124\end{array}$ & $0.000^{*}$ & CDT status & $\begin{array}{l}\text { Pos }=46 \\
\text { Neg }=124\end{array}$ & $0.000^{*}$ \\
\hline Antibiotic use & $\begin{array}{l}\mathrm{Nil}=29 \\
\mathrm{~S} / \mathrm{M}=141\end{array}$ & $0.000^{*}$ & Antibiotic use & $\begin{array}{l}\mathrm{Nil}=26 \\
\mathrm{~S} / \mathrm{M}=144\end{array}$ & $0.000^{*}$ \\
\hline
\end{tabular}

Significant $\mathrm{p}$ values; $\mathrm{FU}$ =follow up; $\mathrm{S} / \mathrm{M}=$ single and multiple; $\mathrm{Abd}=$ abdominal 
variables of patients in the repeat follow-up $(n=47)$ were compared with their data of first $(n=47)$ and second follow-up ( $n=47)$, a significant difference was seen in several variables particularly in antibiotic use, CDT status and presence of mucus (Table 4).

\section{DISCUSSION}

The intestine of a new born infant is sterile. However, by the age of 12 months, the bacterial flora of the infant becomes similar to that of the adult. ${ }^{16} \mathrm{C}$. difficile was initially described as a normal commensal in the intestine of infants ${ }^{17}$ colonizing 15 to $75 \%$ of them ${ }^{18}$ without eliciting observable symptoms. In clear contrast to this, there are a few cases of PMC reported in very young infants and $C$. difficile has been implicated as the pathogen in necrotizing enterocolitis and chronic diarrheic episodes. ${ }^{19-20}$

There have been many disagreements about the pathogenic role of $C$. difficile in infants and young children. But clinical illness in infants of $1-2$ years is rarely reported ${ }^{16}$ as C. difficile is generally not regarded as the etiological agent of CDI in children before adolescence. ${ }^{21}$ Even though CDI is less frequent in children compared to adults, the incidence of CDI in children is rising exponentially ${ }^{22-25}$ because of the emergence of more virulent strains. Boenning et al. ${ }^{26}$ in an emergency service reported C. difficile in $7 \%$ of children with diarrhea and $15 \%$ of controls. In two other studies ${ }^{27,28}$ involving inpatients of $0-2$ years, C. difficile was seen in 11 to $59 \%$ infants with diarrhea and in 24 to $33 \%$ of controls. An association between the presence of $C$. difficile in stool specimens and occurrence of epidemic diarrhea in children attending a day care center has been reported. ${ }^{29}$ In another report ${ }^{30}$ involving inpatient infants, $0-34$ months of age, C. difficile was seen in $21 \%$ of diarrheic infants and $33 \%$ of controls. In another study, ${ }^{31} \mathrm{C}$. difficile was seen in $2.9 \%$ of outpatients, $4.6 \%$ of inpatients, and $6.6 \%$ of controls in the $0-12$ years age group. In an earlier study, Vaishnavi et al. ${ }^{8}$ reported C. difficile toxin in $12.9 \%$ of the diarrheic pediatric samples even without exposure to antibiotics.

Even though stool testing of infants for CDI is not suggested, current information reveals that $26 \%$ of hospitalized children having CDI are infants $<1$ year with $5 \%$ being neonates. ${ }^{22}$ In the present study, CDI was found in $19.5 \%$ of patients in the infant group, $24.5 \%$ patients in the early childhood group and $20.9 \%$ in the teenage group, suggesting that CDI is also not infrequent in children. The asymptomatic carriage has been reported in $15-63 \%$ of neonates, $3-33 \%$ of infants below two years and up to $8.3 \%$ of children above 2 years of age. ${ }^{31}$ Thus because of a high prevalence of asymptomatic carriage C. difficile cannot be assumed to be the etiological agent for diarrhea in young children. ${ }^{21,32}$ The carriage rate of C. difficile is about $37 \%$ for $0-1$-month-old infants and about $30 \%$ for those between 1 and 6 months of age. ${ }^{16}$ However, it is not clear whether these children are asymptomatic carriers or are part of true CDI epidemiology.

Many risk factors can commonly be present in hospitalized patients but that does not establish the etiology of CDI in the given patient as clinical illness is generally not reported before 1 or 2 years in the infants. In the pediatric population, cancer has been reported to be the most important risk factor for acquiring CDI. ${ }^{33}$ In the present study $24.2 \%$ of the children during primary admission had malignant etiology which could have contributed to precipitation of CDI.

Bloody diarrhea is an uncommon symptom in children but when present can lead to fulminant disease like toxic

Table 4: Comparison of variables of repeat follow-up patients with their first follow up and primary admission data

\begin{tabular}{|c|c|c|c|c|c|c|c|c|}
\hline \multicolumn{3}{|c|}{ Repeat follow-up data $(n=47)$} & \multicolumn{3}{|c|}{ 1st Follow-up data $(n=47)$} & \multicolumn{3}{|c|}{ RFU patients' primary admission data $(n=47)$} \\
\hline \multicolumn{2}{|c|}{ Clinical symptoms } & $\begin{array}{l}p \text { value } \\
\text { (Chi- } \\
\text { square) }\end{array}$ & Clinical symptom & & $\begin{array}{c}p \text { value (Chi- } \\
\text { square) }\end{array}$ & Clinical symptom & & $\begin{array}{l}p \text { value } \\
\text { (Chi-square) }\end{array}$ \\
\hline Bloody diarrhea & $\begin{array}{l}\text { Pos }=37 \\
\text { Neg }=10\end{array}$ & $0.000^{*}$ & Bloody diarrhea & $\begin{array}{l}\text { Pos }=30 \\
\text { Neg }=17\end{array}$ & 0.058 & Bloody diarrhea & $\begin{array}{l}\mathrm{Pos}=31 \\
\mathrm{Neg}=16\end{array}$ & $0.029^{*}$ \\
\hline Watery diarrhea & $\begin{array}{l}\mathrm{Pos}=29 \\
\mathrm{Neg}=18\end{array}$ & 0.109 & Watery diarrhea & $\begin{array}{l}\text { Pos }=26 \\
\text { Neg }=21\end{array}$ & 0.466 & Watery diarrhea & $\begin{array}{l}\text { Pos }=19 \\
\text { Neg }=28\end{array}$ & 0.189 \\
\hline $\begin{array}{l}\text { Presence of } \\
\text { mucus }\end{array}$ & $\begin{array}{l}\text { Pos }=8 \\
\text { Neg }=39\end{array}$ & $0.000^{*}$ & $\begin{array}{l}\text { Presence of } \\
\text { mucus }\end{array}$ & $\begin{array}{l}\text { Pos }=7 \\
\text { Neg }=40\end{array}$ & $0.000^{*}$ & $\begin{array}{l}\text { Presence of } \\
\text { mucus }\end{array}$ & $\begin{array}{l}\text { Pos }=6 \\
\text { Neg }=41\end{array}$ & $0.000^{*}$ \\
\hline Fever & $\begin{array}{l}\text { Pos }=20 \\
\text { Neg }=27\end{array}$ & 0.307 & Fever & $\begin{array}{l}\text { Pos }=18 \\
\text { Neg }=29\end{array}$ & 0.109 & Fever & $\begin{array}{l}\text { Pos }=23 \\
\text { Neg }=24\end{array}$ & 0.884 \\
\hline Abd. pain & $\begin{array}{l}\text { Pos }=22 \\
\text { Neg }=25\end{array}$ & 0.662 & Abdominal pain & $\begin{array}{l}\text { Pos }=21 \\
\text { Neg }=26\end{array}$ & 0.466 & Abdominal pain & $\begin{array}{l}\text { Pos }=15 \\
\text { Neg }=32\end{array}$ & $0.013^{*}$ \\
\hline CDT status & $\begin{array}{l}\text { Pos }=15 \\
\text { Neg }=32\end{array}$ & $0.013^{*}$ & CDT status & $\begin{array}{l}\text { Pos }=16 \\
\text { Neg }=31\end{array}$ & 0.029 & CDT status & $\begin{array}{l}\text { Pos }=17 \\
\text { Neg }=30\end{array}$ & 0.058 \\
\hline Antibiotic use & $\begin{array}{l}\mathrm{Nil}=13 \\
\mathrm{~S} / \mathrm{M}=34\end{array}$ & $0.002^{*}$ & Antibiotic use & $\begin{array}{l}\mathrm{Nil}=9 \\
\mathrm{~S} / \mathrm{M}=38\end{array}$ & $0.000^{*}$ & Antibiotic use & $\begin{array}{l}\mathrm{Nil}=9 \\
\mathrm{~S} / \mathrm{M}=38\end{array}$ & $0.000^{*}$ \\
\hline
\end{tabular}

*= Significant $\mathrm{p}$ values; FU = follow-up; RFU = repeat follow up; S/M = single and multiple; Abd = abdominal 
megacolon and death ${ }^{34}$ and will, therefore, need primary care. ${ }^{35}$ In the present study, bloody diarrhea was present in $102(9.87 \%)$ of children during the primary admission with the highest rate of bloody diarrhea among the teenage group patients. Other clinical symptoms like abdominal pain and fever were also significantly present in the pediatric patients with C. difficile positivity.

Data of patients on the first follow-up ( $\mathrm{n}=170$ ) and repeat follow-up $(n=47)$ were compared with their initial admission, which showed that CDT positivity was linked to antibiotic usage. Clinical symptoms such as watery or bloody diarrhea, presence of mucus in stool, fever and abdominal pain were also found to be statistically significant in the follow-up patients, thereby hinting at the possibility of $C$. difficile as the enteropathogen.

\section{CONCLUSION}

The maximum load of infectious diarrhea occurs in economically weak countries, because of insufficient hygiene practice. Our hospital receives patients from all over North India, and the patients belong to various sects of the socio-economic group. Nevertheless, an economic development like global travel, import of food, sewerage, and recreational water facilities also generate occasions for the beginning of transmission of infectious enteropathogens. The strength of this study is that only pediatric patients of various age groups with clinical suspicion of CDI were included so that asymptomatic carriers were largely ruled out. Moreover, data of followup and repeat follow-up patients were investigated and compared with the primary data. The limitation of this study is that patients of age 19 years, though not actually belonging to a pediatric group, were also included in the teenage group as it would have been incorrect to exclude them from the teenage group and therefore some bias may have crept in. Another limitation was that though it was an observational investigation, the data were retrieved retrospectively. However as meticulous records are being maintained in the laboratory, the retrieved data provided sufficient evidence for the prevalence of CDI in children. In conclusion, it may be understood that CDI is also very commonly present in hospitalized pediatric patients, but the final diagnosis should be based on accompanying clinical symptoms and suspicion.

\section{ACKNOWLEDGMENT}

We thank the Institute Ethical Committee for allowing us to analyze the data and Mrs Kamlesh Sharma for secretarial help.

\section{REFERENCES}

1. Mallavarapu R K, Katner, HP. Clostridium difficile-associated diarrhea and colitis in the hospitalized patient; Hospital Physician. Infectious Diseases Society of America Clinical Practice Guidelines for the Diagnosis and Management of Infectious Diarrhea. Hospital Physician July 2007;5: 21-27.

2. George WL. Antimicrobial Agent-Associated Diarrhea in Adult Humans. In Clostridium difficile 1988 Jan 1 pp. 31-44.

3. Vaishnavi, C. Clinical spectrum and pathogenesis of Clostridium difficile associated diseases. Indian J Med Res 2010; 131: 487-499.

4. Vaishnavi C. Clostridium difficile associated disease. In: Infections of the gastrointestinal system. Ed. Vaishnavi C. Jaypee Brothers Medical Publishers. 2013. Pp 87-108.

5. Stark PL, Lee AD, Parsonage BD. Colonization of the large bowel by Clostridium difficile in healthy infants: quantitative study. Infection and immunity. 1982 Mar 1;35(3):895-899.

6. Viscidi R, Willey S, Bartlett JG. Isolation rates and toxigenic potential of Clostridium difficile isolates from various patient populations. Gastroenterol. 1981;81:5-9.

7. Pothoulakis C, Lamont JT. Microbes and microbial toxins: paradigms for microbial- mucosal interactions II. The integrated response of the intestine to Clostridium difficile toxins. Am J Physiol Gastrointest Liver Physiol. 2001;280(2):G178-G183.

8. Vaishnavi C, Thapa BR, Thennarasu K, Singh K. Faecal lactoferrin assay as an adjunct to Clostridium difficile diarrhoea. Indian J Pathol Microbiol. 2002;45(1):69-73.

9. Larson HE, Price AB, Honour P, Borriello SP. Clostridium difficile and the aetiology of pseudomembranous colitis. Lancet; 1978 May 20;1(8073):1063-1066.

10. Cashore WJ, Peter G, Lauermann M, Stonestreet BS, Oh W. Clostridia colonization and clostridial toxin in neonatal necrotizing enterocolitis. J Pediatr.1981;98(2):308-311.

11. Adler SP, Chandrika T, Berman WF. Clostridium difficile associated with pseudomembranous colitis. Occurrence in a 12-week-old infant without prior antibiotic therapy. Am J Dis Child.1981;135(9):820-822.

12. Donta ST, Myers MG. Clostridium difficile toxin in asymptomatic neonates. J Pediatr. 1982;100(3):431-434.

13. Vaishnavi C. Established and potential risk factors for Clostridium difficile infection. Indian J Med Microbiol. 2009 27:291-302.

14. Dominguez SR, Dolan SA, West K, Dantes RB, Epson E, et al. High colonization rate and prolonged shedding of Clostridium difficile in pediatric oncology patients. Clin Infect Dis. 2014;29;59(3):401-403.

15. Vaishnavi C, Singh M, Kapoor P, Kochhar R. Clinical and demographic profile of patients reporting for Clostridium difficile infection in a tertiary care hospital. Indian J Med Microbiol. 2015;33:326-327.

16. Jangi S, Lamont JT. Asymptomatic colonization by Clostridium difficile in infants: implications for disease in later life. J Pediatr Gastroenterol Nutr. 2010;51(1):27.

17. Hall IC, O'Toole E. Intestinal flora in newborn infants with a description of a new pathogenic anaerobe, Bacillus difficilis. Am J Dis Child. 1935;49:390-402.

18. Richardson SA, Alcock PA, Gray J. Clostridium difficile and its toxin in healthy neonates. BMJ (Clin Res Ed).1983;287:878.

19. Han VK, Sayed H, Chance GW, Brabyn DG, Shaheed WA. An outbreak of Clostridium difficile necrotizing enterocolitis: a case for oral vancomycin therapy? 1983;71(6):935-941. 
20. Sutphen JL, Grand RJ, Flores A, Chang TW, Bartlett JG. Chronic diarrhea associated with Clostridium difficile in children. Am J Dis Child.1983;137(3):275-278.

21. Dubberke ER, Gerding DN, Classen D, Arias M K, Podgorny K. Strategies to prevent Clostridium difficile infections in acute care hospitals. Infect Control Hosp Epidemiol. 2008;29 (suppl 1): S81-S92.

22. Kim J, Smathers SA, Prasad P, Leckerman KH, Coffin S, Zaoutis T. Epidemiological features of Clostridium difficile associated disease among inpatients at children's hospitals in the United States, 2001-2006. Pediatrics; 2008; 122(6):1266-1270.

23. Zilberberg MD, Tillotson GS, McDonald C. Clostridium difficile infections among hospitalized children, United States, 1997-2006. Emerg Infect Dis. 2010 Apr;16(4):604.

24. Nylund CM, Goudie A, Garza JM, Fairbrother G, Cohen MB. Clostridium difficile infection in hospitalized children in the United States. Arch Pediatr Adolesc Med 2011;165:451.

25. Deshpande A, Pant C, Anderson MP, Donskey CJ, Sferra TJ. Clostridium difficile infection in the hospitalized pediatric population: increasing trend in disease incidence. Pediatr Infect Dis 2013;32:1138.

26. Boenning DA, Fleisher GR, Campos JM, Hulkower CW, Quinlan RW. Clostridium difficile in a pediatric outpatient population. Pediatr Infect Dis. 1982;1(5):336-338.

27. Mårdh PA, Helin I, Colleen I, Oberg M, Holst E. Clostridium difficile toxin in faecal specimens of healthy children and children with diarrhoea. Acta Paediatr Scand. 1982; 71(2):275-278.
28. Ellis ME, Mandal BK, Dunbar EM, Bundell KR. Clostridium difficile and its cytotoxin in infants admitted to hospital with infectious gastroenteritis. BMJ (Clin Res Ed). 1984;18: 288(6416):524-526.

29. Kim K, DuPont HL, Pickering LK. Outbreaks of diarrhea associated with Clostridium difficile and its toxin in day-care centers: evidence of person-to-person spread. J Pediatr. 1983; 102(3):376-382.

30. Vesikari T, Isolauri E, Mäki M, Grönroos P. Clostridium difficile in young children. As- sociation with antibiotic usage. Acta Paediatr Scand. 1984;73(1):86-91.

31. Cerquetti M, Luzzi I, Caprioli A, Sebastianelli A, Mastrantonio P. Role of Clostridium difficile in childhood diarrhea. Pediatr Infect Dis J. 1995;14(7):598-603.

32. Crew J. Clostridium difficile infection in children: Clinical features and diagnosis. In Eds. Edwards, MS, Torchia, MM, Up to date, 2018.

33. Boyle, NM, Magaret A, Stednick Z, Morrison A, Butler-Wu, S, Zerr $D$ et al. Evaluating risk factors for Clostridium difficile infection in adult and pediatric hematopoietic cell transplant recipients. Antimicrobial resistance and infection control. 2015;4(1):41.

34. Sammons JS, Toltzis P, Zaoutis TE. Clostridium difficile infection in children. JAMA Pediatr. 2013;167(6):567-573

35. Stephen M. Management of bloody diarrhea in children in primary care. BMJ. 2008;336:1010-1015. 